\title{
AS FESTAS E O PROCESSO DE MODERNIZAÇÃO DO TERRITÓRIO GOIANO
}

\section{Feasts and the territorial modernization process in Goiás (Brazil)}

\author{
Carmem Lúcia COSTA ${ }^{1}$
}

\begin{abstract}
RESUMO
O presente trabalho é parte de uma pesquisa que vem sendo realizada no Programa de Pós-Graduação em Geografia Humana da Universidade de São Paulo e tem como objetivo maior problematizar os elementos ligados à reprodução do capital no território goiano, enfocando as transformações e persistências nas práticas socioespaciais dos sujeitos, mais especificamente, os moradores de pequenas cidades do interior, como Catalão - Goiás em que realizamos a nossa pesquisa sobre a Festa em Louvor a Nossa Senhora do Rosário, enfocando o processo de reorganização do território em função das necessidades dos capitais industrial, comercial e financeiro no processo de acumulação flexível. As transformações e as persistências diante da programação da vida cotidiana por interesses globais são analisadas por maio da Festa, percebendo a sua espetacularização e mercadificação, procurando identificar os elementos desse movimento que ajudam a compreender o processo de urbanização do território goiano.
\end{abstract}

Palavras-chave: Produção do espaço; urbano; cultura.

\begin{abstract}
The present text is a part of a research that has been carried by the Program of Post-Graduate Program in Geography Human at the University of São Paulo and it aims at asking questions of the elements to the reproduction of the capital in the goiano territory, focusing the transformations and what persist in the socioespacial practice of the citizens, more specifically, the habitants of small cities, as Catalão - Goiás where we carry through our research on the Festa em Louvor à Nossa Senhora do Rosário, focusing the process of reorganization of the territory in function of the necessities of the capitals industrial, advertising and financier in the process of flexible accumulation. The transformations and the persistance of the programming of the daily life for global interests are analyzed through the Party, perceiving its transformation in speculate and merchandise, looking for to identify the elements of this movement that help to understand the process of urbanization of the Goiano territory.
\end{abstract}

Keywords: Production of space; urban; culture. 


\section{INTRODUÇÃO}

As festas religiosas são parte da cultura do povo brasileiro, um importante elemento na produção da identidade do brasileiro. Festar é a reprodução da vida, a construção de uma sociabilidade, do encontro, do prazer. Em metrópoles ou em pequenas cidades do interior do país, as festas persistem à estratégia capitalista de homogeneização das práticas culturais. Nessa relação entre o velho e o novo as festas persistem, mas transformam-se, uma vez que a cultura é uma prática socioespacial.

Nesse sentido acreditamos ser possível uma leitura do urbano a partir da persistência de práticas festivas em pequenas cidades no interior e como as estratégias capitalistas alcançam-nas e reproduzemnas dentro de uma nova lógica. Importante elemento na construção de identidades e de tradições manifestas em práticas culturais, as festas goianas são um misto de fé, cultura popular, e como em todas as festas, um embate entre o apolíneo e o dionisíaco que se manifesta nas dimensões do sagrado e no profano. Não é nossa pretensão discutir o aparecimento dessas festas, o seu caráter de festa profana ou sagrada. Antes, a proposta é analisar como no processo de modernização do território goiano - via expansão do capital industrial e financeiro - tais práticas persistem, transformam-se ou mesmo deterioram-se. A lógica para a persistência está ligada a esse novo momento de reprodução do capital em que sua expansão alcança práticas cotidianas de construção de identidades e as re-elabora.

Por que algumas festas, e aqui restringimos 0 nosso universo às festas religiosas por entendê-las como práticas socioespaciais dos que fazem parte do processo de construção de identidades do povo goiano, continuaram ou mesmo cresceram em número de participantes e como elemento de atração turística e outras tantas desapareceram das cidades? Como o embate entre o novo e o velho que caracteriza a sociedade moderna territorializa-se em Goiás por meio das festas? Essas são algumas questões que norteiam a reflexão.

Festar é uma forma de preservar tradições, no caso das festas religiosas goianas a fé e a cultura de imigrantes como os negros, estão presentes em grande parte. Enquanto tal essas festas representam as práticas responsáveis pela construção e manutenção de uma identidade local, discurso que se fortalece na sociedade global, dentro da dialética geral $X$ particular. No atual momento de reprodução do capital a identidade local é capturada pela lógica do valor de troca, agregando valor a práticas culturais, tornando-as matéria-prima para a indústria do turismo e do lazer.

O projeto de valorização das culturas locais na sociedade global é uma estratégia do capital que tenta cooptar todas as práticas. Por outro lado essas práticas resistem ao processo de globalização que procura homogeneizar todas as práticas. Enquanto resistências persistem, mas também se transformam com o objetivo de permanecer. Como esse processo está territorializando-se em Goiás é um importante elemento na análise da urbanização, identificando os projetos de mercadificação da cultura goiana e a resistência, o irredutível.

Outra característica importante em grande parte das festas goianas é a presença, desde a origem, das feiras comerciais que entram nas relações de poder e conflitos na produção do espaço-tempo da festa. Essas feiras constituem-se em importantes momentos na realização da circulação do capital no território estabelecendo uma rede entre o global e o local, entre o legal e o ilegal, demonstrando a dimensão do uso da cidade para a reprodução do capital e da cidade como mercadoria. Muitas vezes, estabelece-se o conflito entre o uso da cidade para a festa ou para o capital, mas as estratégias são construídas no sentido da cooptação do uso pela troca, cerceando ao máximo o uso para a festa e procurando agregar valor de troca às práticas festivas. Dessa forma vende-se não apenas os produtos expostos nas feiras, mas toda a festa torna-se mercadoria.

\section{A FESTA COMO UM ELEMENTO TRADICIONAL NO URBANO EM GOIÁS}

As festas em Goiás são marcadas por práticas de fé - trazidas pelos europeus -, pela cultura de povos que migraram para trabalhar em Goiás e pelas feiras em que ocorre a troca de mercadorias. Essas festas sempre ocuparam uma centralidade na vida cotidiana do goiano, principalmente no interior em que as distâncias tornavam o convívio mais difícil, representando as festas, assim, o momento do encontro, do convívio, da aquisição de produtos que vinham do centro do país. Até então as festas eram parte integrante do modo de vida, uma necessidade em cidades pequenas e em fazendas, marcadas pelas distâncias e pelas dificuldades em vencê-las, caracterizando as festas como o espaço-tempo do encontro e das trocas simbólicas e materiais. Com o processo de modernização, cujo objetivo maior era a integração do território brasileiro e a consolidação da sociedade urbana e do modo de vida urbano, algumas dessas práticas perdem espaço e prestígio o que leva ao fim de algumas festas e ao quase desaparecimento de outras. Assim como a identidade local que incor- 
pora elementos do global e interfere nessa dimensão, também as festas que persistem vão incorporar novos elementos à sua lógica simbólica e prática, ou conforme argumenta Farias (2005, p. 650) as alianças tecidas entre as singularidades étnico-históricas e as determinações de uma lógica do capital, uma lógica que segundo o autor é "definida pela capacidade de flexibilizar e, com isto, articular símbolos e espaços à sua dinâmica de auto-rentabilidade." Esse é o caminho que agrega valor de troca a práticas consideradas ultrapassadas, reorganizando-as dentro da nova lógica de mercado, redefinindo o uso do espaço da festa.

Para a análise desse processo recorremos ao que Lefebvre (1992) denomina de níveis de análise da realidade e a relação dialética entre os mesmos. O nível global expressa as estratégias do capital e do Estado no sentido de organizar, programar o espaço e a vida cotidiana. Nesse nível são elaboradas políticas de intervenção, de programação do nível misto - as cidades - e do nível privado - a vida cotidiana. Dessa forma é necessário pensarmos a permanência de algumas dessas festas dentro de um projeto elaborado no nível global e também como forma de resistência às cooptações do global no uso da cidade. O projeto elaborado no nível global leva em conta o novo papel da cidade, agora mercadoria que necessita ser consumida e, um dos caminhos para tal consumo é a valorização de práticas que revelam a identidade local, ou seja, algo que faz daquela cidade um produto com características específicas, locais que a faz ser única na sociedade global. Mas esse processo não se dá sem conflito.

Nesse sentido podemos analisar a permanência das festas religiosas como resistência de um modo de vida da periferia, do interior, mas que também está em processo de valorização, sendo cada vez mais apropriada pelo valor de troca. Assim o que antes era apenas uma prática de uso da cidade para a realização da vida, adquire o caráter de espetáculo que é o primeiro passo para a mercadificação (SANTANA, 2007) de tais práticas, com objetivo a programar o uso da cidade para a reprodução do capital, alcançando a vida cotidiana e reinventando tradições (HOBSBAWN, 1998), reorganizando as práticas, elaborando discursos de racionalização e fortalecendo a imagem que é transformada em "simulacros materiais na forma de ambientes, eventos, espetáculos, etc." (BEZERRA, 2007, p. 02). A transformação da festa em simulacro é resultante de uma estratégia global que, conforme argumenta Hall (1997), "[...] quanto mais importante - mais central - se torna a cultura, tanto mais significativas são as forças que a governam, moldam e regulam." A festa vai sendo cerceada em função de interesses que Ihes são estranhos, externos.

A necessidade da realização do mundo da mercadoria hoje exige a programação da sociedade em seus diversos níveis: o econômico - por meio do desenvolvimento tecnológico e da ciência que procura otimizar o tempo e o espaço do trabalho e do não trabalho; o político - com o novo papel do Estado que "cola" no econômico e desenvolve as estratégias para a realização do econômico por meio do controle e da vigilância; e o social - com a produção da vida cotidiana, com as práticas redutoras, programadas, espaços reguladores e regulados.

A programação da sociedade para o consumo como modo de reprodução, exige a articulação do econômico e do político no sentido de cooptar o social para a realização do ciclo de consumo e, assim, a vida cotidiana é invadida por estratégias, práticas, signos, imagens, informações que procuram homogeneizar, eliminar as resistências, reproduzir um cotidiano marcado pela repetição, pelo tempo do relógio, pelo controle, pelos simulacros, pelas representações e pelo discurso. Nesse sentido o vivido é invadido pelo discurso que transforma as práticas socioespaciais, o espaço, o tempo, a vida com o objetivo do consumo dos padrões globais ditados pelo capital. Nesse caminho, um novo padrão de cultura é imposto a partir de um pensamento único que procura homogeneizar os espaços, impor uma cultura global.

Mas, conforme Lefebvre argumenta, o processo é dialético e há a resistência. As culturas locais, práticas socioespaciais de construção de identidades locais resistem à homogeneização e em tal processo exigem uma nova estratégia global que "permita" e ganhe com a sua resistência. É nesse sentido que algumas práticas que a priori foram consideradas ultrapassadas, velhas, são revalorizadas, uma vez que a sua permanência precisa se inserir no circuito da troca, tornando-se mais um produto que a cidade oferece para o consumo ou para o consumo da própria cidade. Nesse processo as transformações podem comprometer ou até mesmo deteriorar a rede simbólica das festas, como argumenta Maia (2002) ao chamar a atenção para a perda da tradição em tais festas e como podemos observar na eliminação de alguns ritos em algumas festas para que essas possam ser mais atraentes, colocando a tradição em segundo plano, priorizando a imagem.

O urbano é marcado pelo consumo da imagem, com apelo muito forte dos meios de comunicação, utilizados para divulgar os produtos oferecidos por cada 
lugar na guerra pelo consumidor, pelo turista. De acordo com Bezerra (2007, p. 4), "a festa, neste contexto das representações, assume um papel importante, pois seu caráter tanto material quanto simbólico contribui para que ela assuma a função de produtora de uma identidade da cidade." Uma identidade que é, agora, uma mercadoria a ser vendida pela cidade aos turistas que chegam de todos os lugares para consumirem o simulacro da festa, uma vez que a imagem se sobrepõe à tradição, aos rituais, à história de vida dos que fazem a festa ou mesmo os conflitos colocados nesta produção. Ainda de acordo com a autora,

Neste cenário das imagens e das representações sobre a cidade, a festa, tem ganhado uma centralidade, pois seu poder de impressionar, seu caráter estético e ao mesmo tempo simbólico, tem contribuído para que ela assuma o papel de representação da identidade local.

Esse processo pode ser observado em várias cidades goianas e com suas festas como as Cavalhadas de Pirenópolis, a procissão do fogaréu na Cidade de Goiás, a Exposição Agropecuária em Goiânia, a Festa do Divino Pai Eterno em Trindade e a Festa em Louvor a Nossa Senhora do Rosário em Catalão, para citar algumas. Nesse sentido, conforme já apontamos em outros textos, os elementos da construção do urbano em Goiás - a fé, a festa e a troca - estão em processo de re-elaboração em função das necessidades do atual momento de reprodução do capital em Goiás.

Nesse contexto, é relevante a análise do processo de espetacularização e mercadificação da cultura goiana, lembrando que ser espetáculo é o primeiro passo para tornar-se mercadoria e, talvez esteja aí um dos motivos para que algumas festas goianas que recusaram o caráter espetacular terem desaparecido como prática. As práticas que persistem espetacularizaramse e algumas já se encontram em processo avançado de mercadificação como a Exposição Agropecuária de Goiânia. Cabe lembrar que na sociedade urbana a estratégia de cooptação das práticas culturais obedece à lógica do atual momento de expansão do capital financeiro e comercial. Nesse sentido Farias (2005, p. 652) demonstra o caminho percorrido para alcançar a cultura, em suas palavras,

A ampliação dos serviços de crédito ao consumidor e do sistema comercial de comunicação, calcada no mercado publicitário, permite que a propensão ao consumo de bens veiculados pelo mercado irrompa no campo das subjetividades, sintonizado agora com o aceleramento da subsunção dos modos de experiência individual e coletiva ao intercâmbio viabilizado pelo dinheiro (FARIAS, 2005, p. 652).
O mesmo autor discorre ainda sobre a circulação cada vez maior de dinheiro em festas populares por todo o Brasil, o que evidencia a cooptação das festas populares e sua inserção no circuito de realização do capital. Mais adiante 0 autor lembra que "A dinâmica do consumo, ativada nesse nicho mercadológico, estabelece outras funções à organização e expressão da cultura", ou ainda de acordo com Debord (1997, p. 13) "tudo o que era vivido diretamente tornou-se uma representação." Assim as festas tornam-se representação do que já foram e, como representações, "são verdadeiras como respostas aos problemas reais e falsas como dissimuladoras das finalidades reais." (LEFEBVRE, 1983, p. 62).

A finalidade real é a mercadificação, e o processo tem sido o caminho para a persistência de grande parte das festas populares. Mas como o próprio Lefebvre argumenta, o círculo não se fecha totalmente e as fissuras no processo, as resistências, o uso, a vida que se reproduz nessas práticas festivas não desaparece. Nesse sentido nos propomos a refletir sobre as transformações e as persistências na Festa em Louvor a Nossa Senhora do Rosário em Catalão, no interior de Goiás, para assim alcançarmos alguns elementos que auxiliem na leitura da urbanização no estado. A Festa em Louvor a Nossa Senhora do Rosário foi escolhida, em primeiro lugar por ser uma prática da cidade em que nasci e assim pude acompanhar de perto as transformações na festa; em segundo lugar, a escolha deu-se em função da atuação de grupos organizados da sociedade civil, do capital e do estado no sentido de torná-la uma atração turística, discurso envolto pela valorização da cultura local.

\section{O ESPAÇO-TEMPO DA FESTA EM LOUVOR A NOSSA SENHORA DO ROSÁRIO: ALGUNS APONTAMEN- TOS}

A Festa em Louvor a Nossa Senhora do Rosário em Catalão, na região sudeste de Goiás, existe oficialmente como festa na cidade há mais de cento e trinta anos. No entanto há relatos de moradores mais antigos e dos que fazem a Festa em Catalão de sua existência há bem mais tempo. Já em 1820 temos a construção da Igreja de Nossa Senhora dos Homens Pretos em que, posteriormente, em torno da qual a cidade cresceria. Numa prática bastante comum em Goiás o "povoamento de patrimônio" (GÓMEZ, 1994), com a doação de terras por fazendeiros que queriam agregar valor às suas terras e, também, agradecer alguma graça recebida de algum santo ou santa católica. No caso de Catalão a santa foi Nossa Senhora do Rosário, uma santa para a qual os devotos das comunidades negras faziam à festa 
das Congadas, desde a chegada no Brasil.

Esse elemento demonstra que no sudeste goiano os negros que chegaram para trabalhar como mão-deobra escrava nas lavouras da região ou na mineração, permaneceram, constituíram famílias e preservaram suas tradições. Mas como minoria e segregados da apropriação das riquezas que produzem, os negros lutam muito pelo direito de fazer as suas festas no Brasil, sendo algumas práticas ainda discriminadas. Em Catalão, por exemplo, esse conflito aparece no processo de perda da Igreja no século XIX com a chegada de padres franciscanos, e atualmente, com a pressão da expansão do centro comercial da cidade que já alcança o território da Festa, colocando em risco a permanência da dessa nesse lugar.

A disputa pelo espaço-tempo da Festa aponta o movimento dialético da sociedade e a disputa na apropriação do espaço, pelo direito à cidade. Assim temos de um lado as estratégias globais representadas por práticas estatais com políticas que garantem a fluidez do capital na cidade, o capital industrial e comercial que representam os maiores investimentos. Essas estratégias alcançam o modo de vida dos moradores e transformam as suas práticas. A cidade torna-se mercadoria onde os que podem consomem as mercadorias variadas, inclusive o espaço, e os que não possuem condições para tal, consomem os simulacros. Na luta pela vida a dimensão simbólica é um fator importante, já que não necessitamos apenas de bens materiais para a reprodução da vida. Conforme já apontamos, também esse universo simbólico é objeto de cooptação, de estratégias globais de programação. É a reprodução do urbano, conforme aponta Carlos (2001, p.180):

A reprodução, no momento atual, realiza-se por meio da programação da vida cotidiana - como possibilidade de instauração do cotidiano - que surge invadida pelo mundo da mercadoria, produtora da uniformidade sob a forma das aparências diferenciadas das coisas e geradoras do tempo de lazer como organização da sociedade de consumo. Isto porque as relações entre processo de produção e o desenvolvimento das forças produtivas criam, no mundo moderno, novas possibilidades de realizar a acumulação, que em sua fase atual liga-se cada vez mais à produção do espaço - produção que se coloca em uma nova perspectiva, em que novos valores de troca ganham valor de uso pela extensão, no espaço, do valor de troca.

O pensamento da autora soma-se a de outros autores citados aqui para apontar a cooptação da vida cotidiana pela sociedade de consumo, inclusive cooptando as suas práticas festivas e reproduzindo-as dentro de uma outra lógica. Em Catalão, desde os últimos anos do século $X X$, a reprodução do urbano está sob estratégias do capital industrial e comercial aliado às elites locais que procuram promover o desenvolvimento econômico da cidade. Nesse movimento a Festa ganha centralidade na vida social por meio do processo de valorização que não se dá sem a intervenção do estado e dos sujeitos envolvidos na Festa. De acordo com Bezerra (2005, p. 2) quanto mais centralidade a festa adquire, "tanto mais significativas são as forças que a governam, moldam e regulam." É nesse contexto que o espaço-tempo da Festa em Catalão acontece.

A regulação do espaço-tempo da Festa é feita como estratégia de "organizar" o espaço da festa, colocar limites de uso, cercear o desejo em nome do espetáculo que exige comportamentos e novos valores. A dialética entre o velho e o novo acontece e o conflito entre a tradição e o novo repete o dilema de mudar para permanecer ou desaparecer. No caso da Festa em Catalão observamos o interesse em promovê-la como atração turística da cidade, enquadrando-se dentro da lógica capitalista descrita acima. Essas estratégias são realizadas pelo poder público municipal, pela mídia e pelos próprios dançadores que esperam, assim, alcançar o reconhecimento da comunidade e a valorização da sua prática, inclusive obtendo ganhos materiais com o processo.

A espetacularização da Congada contribuiu para o aumento do número de grupos e de dançadores que hoje já somam em torno de três mil; o processo também originou transformações nos rituais, nas coreografias, nas letras das músicas, nas vestimentas, nos instrumentos musicais, nos percursos. Fazer a festa para o outro exige uma atenção com a imagem que agora precisa ser mais colorida e atrativa; o som das caixas precisa ser mais empolgante, o público precisa ser envolto pelo ritual, mesmo sem o compreender muito bem. É assim que temos uma valoração da Congada e não o reconhecimento de uma cultura popular, afinal as pessoas que assistem ao espetáculo desconhecem, em grande parte, a história de vida dos dançadores e a história da Congada como prática da cultura negra, não compreendem o sentido dos rituais e os valores, consumindo apenas as imagens. É claro que para o dançador a simbologia da Festa é outra, assim como para os devotos a fé é o motor maior de sua realização. A multidimensionalidade da Festa é um dos elementos responsáveis pela sua continuidade como prática socioespacial das festas. 


\section{CONSIDERAÇÕES FINAIS}

As transformações alcançam o espaço profano, o espaço sagrado e o espaço do comércio e reproduz a festa como mercadoria, processo que faz parte de um projeto global de expansão do circuito de realização do capital. A cooptação das práticas festivas, do desejo, do uso da cidade para a vida realiza-se com as estratégias que programam a vida cotidiana e re-elaboram suas práticas, característica da vida urbana moderna.

Mostrar como o processo de cooptação alcança as práticas festivas revela o cerceamento do direito à cidade, do lazer para todos, do uso da cidade para a vida em prol dos interesses estranhos e distantes do capital. Mas, por outro lado buscamos também os elementos da persistência que apontam à possibilidade da construção de um outro modo de vida urbano, de um outro espaço, de uma outra lógica de produção do espaço.

Festar ainda é, mesmo que em processo de cooptação, a realização da vida e de toda uma dimensão da reprodução social que ainda carece de estudos em busca de outras possibilidades, da realização de práticas libertárias e mais justas, de uma cidade para todos. $\mathrm{Na}$ contramão desse pensamento, o capital apropriase do espaço-tempo das cidades impondo a lógica da fluidez, do movimento, da efemeridade, da imagem, dos simulacros. Mas a dimensão da riqueza da vida cotidiana persiste, assim como nas práticas festivas dos Congadeiros em Catalão, uma comunidade excluída, segregada, discriminada, mas não deixa de praticar festivamente a vida.

Persistir mesmo que se transformando revela estratégias de sobrevivência do homem diante de uma política que tudo quer homogeneizar e padronizar. Em vários momentos da Festa em Louvor a Nossa Senhora do Rosário percebemos as estratégias estabelecidas em todas as dimensões que compõem esse espaçotempo, desde os Congadeiros aos feirantes, maneiras de apropriar-se do espaço que não foi planejado para eles, apropriações que produzem o lugar com sua identidade que se torna tão cara ao capital hoje, cada vez mais carente de novas mercadorias.

Nesse processo de espetacularização e mercadificação da cultura goiana, observamos que algumas festas tornaram-se grandes eventos com capacidade de atração de turistas de várias partes do país. Outras práticas ainda vivenciam a disputa entre o tradicional e o novo. Esses elementos são parte integrante da reprodução do urbano em Goiás com sua modernidade que convive com velhas práticas que compõem o "ser goiano." Fica ao final desta reflexão a necessidade de mais estudos e pesquisas nesta área com objetivo de melhor compreender como o capital e a vida reorganizam o território goiano.

\section{REFERÊNCIAS}

DEUS, João B. de. Transformações sócioespaciais e as diferenças regionais em Goiás. In: ENCONTRO DE GEÓGRAFOS DA AMÉRICA LATINA, 10. Anais... São Paulo, 2005.

BRANDÃO, Carlos R. A Festa do Santo de Preto. Goiânia: UFG, 1985.

BEZERRA, Amélia C. A. Cidade, Cultura e Planejamento em Tempo de Espetáculo. In: ENCONTRO NACIONAL DAANPEGE, 7, 2007, Niterói. Anais... Niterói: 2007. 1 CD-ROM.

CARLOS, Ana F. O lugar no/do mundo. São Paulo: Hucitec, 1996.

$\frac{\text { A }}{1995 .}$ (re)produção do espaço urbano. São Paulo: Edusp,
$\frac{\text { 2001. Espaço-Tempo na Metrópole. São Paulo: Contexto, }}{}$

DEBORD, Guy. A sociedade do espetáculo. Rio de Janeiro: Contraponto, 1997.

FARIAS, Edson. Economia e Cultura no Circuito das Festas Populares Brasileiras. Revista Sociedade e Estado. Brasília, v. 20, n. 3, 2005.

GÓMEZ, Luiz P. História da cidade de Catalão. In: História Política de Catalão. Goiânia: Edufg, 1994. p. 21

HALL, S. A centralidade da cultura: notas sobre as revoluções culturais do nosso tempo. Revista Educação e Realidade. Porto Alegre. v. 22, n. 2, jul./dez, 1997.

HARVEY, David. A Condição Pós-moderna. São Paulo: Loyola, 1992.

HOBSBAWN, Eric.; RANGER, Terence (Org.). A invenção das tradições. Rio de Janeiro: Paz e Terra, 1997

LEFEBVRE, Henri. Vida cotidiana no mundo moderno. São Paulo: Ática, 1991.

. La revolución urbana. Madrid: Alianza, 1983.

O direito à cidade. São Paulo: Moraes, 1991a.

. Espacio y politica. Madrid: Península, 1976.

Critique de I avie quotidienne. Introduction. Paris:

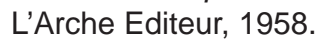


MAIA, Carlos E. S. Enlaces Geográficos de um Mundo Festivo - Pirenópolis: a tradição cavalheiresca e sua rede organizacional. Rio de Janeiro, Tese (Doutorado) - PPGG/UFRJ, 2002.

MAIA, Doralice S. A Geografia e o estudo dos costumes e das tradições. In: Terra Livre. São Paulo: AGB, n.16, $1^{\circ}$ sem. 2001.

MOURA, Clovis. Dialética radical do Brasil Negro. São Paulo: Editora Anita, 1994.

PRADO, Patrícia do. Congada, corpo e cultura na $125^{a}$ Festa em Louvor a Nossa Senhora do Rosário. Dissertação (Mestrado) - Unicamp, Campinas, 2003.
PAULA, Maria H. Cantigas das Congadas de Catalão - aspectos linguísticos e identidade cultural. Dissertação (Mestrado) - UFG, Goiânia, 2000.

SANTANA, Paola V. de. Maracatu: a centralidade da periferia. Tese (Doutorado) - Departamento de Geografia, FFLCH/USP, São Paulo, 2006.

KATRIB, Cairo M. Nos mistérios do Rosário: as múltiplas vivências da Festa em Louvor a Nossa Senhora do Rosário - Catalão (1936 - 2003). Dissertação (Mestrado) - UFU, Uberlândia, 2004. 
